\title{
Surgical angioplasty of the left main coronary artery in non-atherosclerotic lesions
}

\author{
R Prêtre, M I Turina
}

\begin{abstract}
Surgical angioplasty of the left main coronary artery confers several advantages over conventional bypass surgery: unrestricted forward flow is provided to the entire coronary bed and graft material is spared. The literature contains many reports of surgical angioplasty of atherosclerotic stenoses. The technique is described in five patients with nonatherosclerotic disease of the left main coronary artery: three children (a 7 year old girl who had undergone an arterial switch operation shortly after birth; a 9 year old boy with congenital supravalvar aortic stenosis; and a 10 year old girl with Kawasaki's disease) and two adults (a 51 year old woman with post-radiation stenosis; a 53 year old man with acute dissection). All patients had an uneventful recovery and are free from symptoms with a widely open left main trunk. Although technical difficulties are increased in these patients, excellent results can be achieved with this approach.

(Heart 2000;83:91-93)
\end{abstract}

Keywords: surgical angioplasty; paediatric cardiology; non-atherosclerotic lesions; congenital heart defects

The haemodynamic characteristics restored after angioplasty of a stenotic left main coronary artery are superior to those obtained after conventional aortocoronary bypass to the major branches of the left coronary arterial tree. ${ }^{12}$ Because ideal conditions are rarely fulfilled and the repair is technically demanding, surgical angioplasty of the left main coronary artery is not widely used. ${ }^{13}$ The procedure is generally restricted to myocardial revascularisation in patients with atherosclerotic lesions. We report here its application to other groups of patients with anticipated increased technical difficulties.

Surgery, University Hospital Zürich, 100 Rämistrasse, 8091 Zürich, Switzerland R Prêtre

M I Turina

Correspondence to: Dr Prêtre

email: rene.pretre@

chi.usz.ch

Accepted for publication 22 July 1999 between 1995 and 1998. The operation performed with the aid of cardiopulmonary bypass and during a period of cold blood cardioplegia. The patients or their physicians were contacted at the end of 1998 to update follow up.

CASE 1

A newborn baby with d-transposition of the great arteries underwent an arterial switch operation. The coronary arteries originated from the corresponding facing sinuses. They were harvested and reimplanted with a button of aortic wall on the neo-ascending aorta. The Lecompte manoeuvre of the great arteries was performed, and the neo-pulmonary artery, reconstructed with autologous pericardium, was sutured without tension to the pulmonary bifurcation. The child did not have signs of myocardial ischaemia. Left ventricular ejection fraction was normal and contraction homogenous. The child grew normally.

At age 7 years she started to complain of effort angina pectoris. Angiography revealed a stenosis at the implantation of the left coronary artery. Reoperation revealed dense pericardial adhesions. The left pulmonary artery was transected at the pulmonary bifurcation to allow mobilisation of the main pulmonary artery and access to the left coronary artery. The origin of the left coronary artery was dissected away from scar tissue that was responsible for the stenosis. A longitudinal incision was carried out in the coronary artery from its implantation on the aorta to a few millimetres distal to the stenotic segment and a patch of autologous saphenous vein used to enlarge the origin of the coronary artery. The left pulmonary artery was sutured back on the pulmonary bifurcation. Recovery was uneventful. The child, now 10 years old, is free from symptoms.

\section{CASE 2}

A 9 year old boy underwent correction of a diffuse form of congenital supravalvar aortic stenosis, that extended from the aortic root to the beginning of the descending aorta. ${ }^{4}$ Angiography also revealed a stenosis at the origin of the left coronary artery trunk. The left ventricle was hypertrophic with normal systolic function. At surgery, the beginning of the stenosis on the aorta ascendens was sharply demarcated. The involvement of the origin of the left coronary ostium was confirmed. The aortic root was remodelled with separate patches of pericardium that were used to enlarge the sinotubular junction between all three commissures. In the 

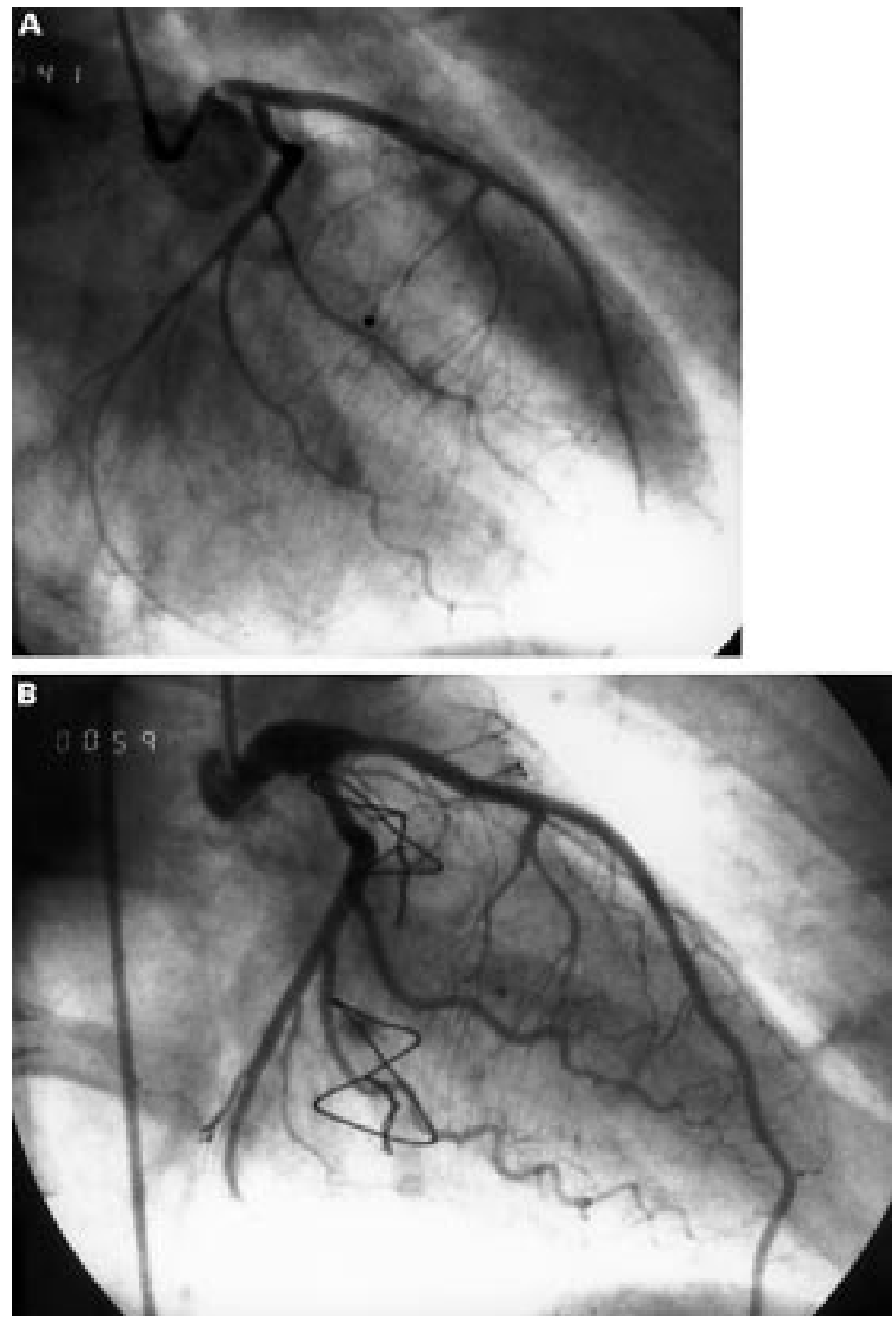

Figure 1 (A) Preoperative and (B) postoperative angiography of the left main coronary trunk of case 4, showing an excellent result of angioplasty with brisk opacification of the whole left coronary tree. sion was prolonged beyond the stenosis. The excess wall of the aneurysm was resected and a patch of autologous saphenous vein was used to enlarge the outlet stenoses. The arteriotomy was closed over a $3 \mathrm{~mm}$ probe to harmoniously calibrate the artery diameter. Because additional stenoses existed on the proximal left anterior descending artery, the left internal mammary artery was harvested and implanted on its distal half. Postoperative course was uneventful. Angiographic control at three months showed a non-restrictive left main trunk with rapid filling of the circumflex and proximal left anterior descending artery, and a patent internal mammary artery filling the distal left anterior descending artery. The child is free from symptoms 15 months after surgery.

CASE 4

A 51 year old woman presented with increasing angina pectoris 13 years after radiotherapy of the left chest for a breast carcinoma. Coronary angiography revealed a high grade stenosis of the left main coronary artery and an occlusion of the right coronary artery. The mammary arteries were hypotrophic. At surgery, the tissues were adherent to each other. After tedious dissection of the pulmonary artery, the left main coronary trunk was exposed up to its bifurcation. It was opened longitudinally and patched with a strip of autologous pericardium. A venous bypass was performed on the right coronary artery. Postoperative course and follow up (extending to 24 months) were uneventful. Coronary angiography showed a patent left main trunk and rapid opacification of the coronary arteries (fig 1).

CASE 5

A 53 year old man underwent aortic valve replacement for stenosis with a mechanical prosthesis. One year later, while digging in his garden, he felt excruciating pain in the chest owing to acute type A aortic dissection. ECG showed no signs of ischaemia, and transoesophageal echocardiography showed normal ventricular function. After aortic cross clamping, the ascending aorta was transected above the aortic root. The dissection was circumferential and involved the origin of both coronary arteries. During mobilisation of the intimal flap, it appeared that a $2 \mathrm{~cm}$ long sequester of intimal tissue, originating from the left coronary artery trunk, was flapping in the false lumen of the aorta. The adventitial layer of the dissected coronary artery trunk was very thin with several tiny holes. The pulmonary artery was extensively dissected and retracted to permit complete exposure of the coronary artery trunk. Full thickness of the coronary artery wall was found in the middle of the trunk, about $12 \mathrm{~mm}$ proximal to the bifurcation. The trunk was opened longitudinally along its anterior surface up to the bifurcation. A segment of autologous saphenous vein was appropriately bevelled and end-to-end anastomosed to the coronary trunk. The aortic valve prosthesis was replaced with a composite graft. The layers of the dissected origin of the right coronary artery was fixed together with fibrin glue. Both ventricle had a normal function -wi contraction abnormality. At surgery, the aneurysms were opened longitudinally and the inci- 
coronary arteries were reimplanted in the graft, and the graft was sutured distally onto the aortic arch. Postoperative course was uneventful and the patient resumed his active live. Regular chest computed tomography showed no dilatation of the dissected aorta. Magnetic resonance imaging three years later showed unrestricted flow in the left main trunk.

\section{Discussion}

Restitution of normal blood flow through the left main coronary artery confers advantages over multiple and sequential bypass surgery to more distal branches. Occlusion of the main coronary trunk is prevented, antegrade perfusion to the entire coronary bed provided, competitive flow avoided, and bypass material spared. In a young patient, who may later present with recurrent coronary artery disease, these advantages are substantial. Conventional percutaneous transluminal angioplasty may still be performed or, if surgery is required, the risk of damaging a bypass at sternum re-entry or provoking coronary embolisation during dissection of a stenotic bypass is avoided. Finally, reconstruction of the main coronary trunk provides the shortest and most efficient way for blood to leave aorta (which acts as a volume capacitance) to the myocardium. The shortness and relatively large size of proximal native coronary arteries, in comparison to any bypass conduit, provide optimal conditions for myocardial perfusion under maximal stress as occurs during intense exercise.

Surgical angioplasty of the left main coronary trunk was attempted in the early days of cardiac surgery. ${ }^{5-7}$ The procedure, however, fell into disgrace because of frequent dire complications and unpredictable results, while venous and arterial aortocoronary bypasses became safe and reproducible. ${ }^{8} \mathrm{~A}$ few groups, however, showed that surgical angioplasty of the left main coronary artery provides excellent results when stringent selection criteria and rigorous surgical technique are applied. ${ }^{29-12}$ Patients with isolated, non-calcified lesions confined to the proximal half of the coronary trunk are the best candidates.

We never abandoned the procedure in our atherosclerotic patients, and we offered it to other patients who, despite enhanced technical difficulties, would particularly benefit from the ideal haemodynamic characteristics restored. ${ }^{13-16}$ Three of our patients were children with the prospect of a long life. Coronary artery bypass with the internal mammary artery has been successfully performed in children. ${ }^{17-19}$ Although the long term outlook of arterial grafting to the coronary arteries is excellent in adults, it may not be optimal in the young, especially if the child later indulges in intense physical activities.

The availability of a suitable arterial conduit was the main problem in our case 4 , because the internal mammary arteries were hypo- trophic after radiotherapy. A patch of autologous vein would have theoretically been superior to autologous pericardium for the angioplasty, because of intrinsic fibrinolytic properties and, in this case, absence of possible radiation damage. A piece of thin, macroscopically normal pericardium found on the right side of the heart was, however, used. In case 5, surgical angioplasty of the coronary trunk avoided bypass to the coronary artery branches, which would have been difficult to find in a reoperation and without the aid of preoperative coronary angiography. Furthermore, the use of pedicled internal mammary arteries to graft coronary arteries may be dangerous in a fresh aortic dissection. The dissection frequently involves the arch arteries and may prevent adequate flow in their branches. ${ }^{20}$

The excellent clinical course of our patients validate the use of surgical angioplasty of the left main coronary artery in non-atherosclerotic lesions. Longer follow up will tell if the repair remains effective.

1 Dion R, Verhelst R, Matta A, et al. Surgical angioplasty of the left main coronary artery. I Thorac Cardiovasc Surg 1990;99:241-9.

2 Dion R, Elias B, El Khoury G, et al. Surgical angioplasty of the left main coronary artery. Eur f Cardiothorac Surg 1997; 11:857-64.

3 Deuvaert FE, De Paepe J, Van Nooten G, et al. Transaortic saphenous patch angioplasty for left main coronary artery stenosis. An alternative to coronary artery bypass. $\mathcal{F}$ Cardiovasc Surg Torino 1988;29:610-13.

4 Prêtre R, Arbenz U, Vogt P, et al. Application of successive principles of repair to correct supravalvular aortic stenosis. Ann Thorac Surg 1999;67:1167-9.

5 Bailey CP, Lemmon WN. Survival after coronary endarterectomy. FAMA 1957;164:641-6.

6 Effler DB, Sones FM, Favarolo RG, et al. Coronary endarterectomy with patch graft reconstruction. Ann Surg 1965; 162:590-601

7 Sabiston DC, Ebert PA, Friesinger GC, et al. Proximal endarterectomy: arterial reconstruction for coronary occlusion at aortic origin. Arch Surg 1965;91:758-64.

8 Favarolo RG, Effler DB, Groves LK, et al. Severe segmental Favarolo RG, Effler DB, Groves LK, et al. Severe segmental
obstruction of the left main coronary artery and its division: surgical treatment by the saphenous vein graft division: surgical treatment by the saphenous vein graf

9 Bergelson BA. Left main coronary artery disease: assessment, diagnosis, and therapy. Am Heart f 1995;129:350-9.

10 Briffa NP, Clarke S, Kugan G, et al. Surgical angioplasty of the left main coronary artery: follow-up with magnetic resonance imaging. Ann Thorac Surg 1996;62:550-2.

11 Hitchcock JF, Robles de Medina EO, Jambroes G. Angioplasty of the left main coronary artery for isolated left main coronary artery disease. 7 Thorac Cardiovasc Surg 1983;85:880-4

12 Meseguer J, Hurle A, FernandezLatorre F, et al. Left main coronary artery patch angioplasty: midterm experience and follow-up with spiral computed tomography. Ann Thorac Surg 1998;65:1594-7.

13 Chun PK, Jones R, Robinowitz M, et al. Coronary ostial stenosis in Takayasu's arteritis. Chest 1980;78:330-1.

14 Gaudiani VA, Siegel SB, McIntosh Yellin NL. Left main coronary artery reconstruction after radiation therapy. $A n n$ Thorac Surg 1994;58:567-9.

15 Musiani A, Cernigliaro C, Sansa M, et al. Left main coronary artery atresia: literature review and therapeutical considerations. Eur f Cardiothorac Surg 1997;11:505-14.

16 Ross DB, Rebeyka IM, Coles JG, et al. Surgical angioplasty of the left main coronary artery in a 12 -year-old child [letter]. F Thorac Cardiovasc Surg 1993;106:943-4.

17 Brackenbury E, Gardiner H, Chan K, et al. Internal mammary artery to coronary artery bypass in paediatric cardiac surgery. Eur f Cardiothorac Surg 1998;14:639-42.

18 Bonnet D, Bonhoeffer P, Aggoun Y, et al. Coronary bypass surgery in children: results in 6 cases. Arch Mal Coeur 1998;91:581-5.

19 Mavroudis C, Backer CL, Muster AJ, et al. Expanding indications for pediatric coronary artery bypass. $\mathcal{F}$ Thorac Cardiovasc Surg 1996;111:181-9.

20 Prêtre R, von Segesser LK. Aortic dissection. Lancet 1997;349:1461-4. 